\title{
0 Conceito de Serviço
}

\author{
DIMÁRIA SILVA E M EIRELLES*
}

The Concept of Service. The service sector involves a wide range of activities, each with different product characteristics, process and market organizations. Intending to take into account their specificities, without binding to particularities and exceptions, this paper, through a revision of classic and contemporary authors, proposes a group of contributive elements for a conceptual approach.

Key-words: service; terciary sector; theories of value; classification of service activities.

JEL Classification: L800.

\section{INTRODUÇÃO}

Desde os trabalhos iniciais de Fischer (1939) e Clark (1940), onde se detecta um grupo de atividades de expressiva participação na composição do produto interno bruto, denominado por estes autores de setor terciário, vários têm sido os esforços teóricos e analíticos empreendidos na busca da compreensão das particularidades e especificidades do setor de serviços.

A gregando uma diversidade de atividades, o setor prima pela heterogeneidade e variedade, seja em termos das características de produto e de processo, seja do ponto de vista das estruturas de mercado, heterogeneidade esta que se reflete no tratamento teórico dado ao setor. Conforme apresentado por Kon (2004), a base de conceituação e classificação das atividades de serviço é bastante variada, e a indefinição quanto às diferenças entre bens e serviços ainda permanece no debate atual. ${ }^{1}$

\footnotetext{
* Doutorado e mestrado em economia industrial e da tecnologia pela Universidade Federal do rio de Janeiro e Graduação em Ciências Econômicas pela Universidade Federal de Uberlândia. E-mail: d.meirelles@ig.com.br. Submetido: Julho 2004, aceito: A bril 2005. Submetido: Julho 2004, aceito: Abril 2005.

${ }^{1}$ As divergências do discurso contemporâneo são bastante conhecidas no que se refere ao papel do setor de serviços no desenvolvimento econômico, haja visto o debate entre autores " pós-industrialistas", que defendem o setor como o principal responsável pelo processo de desenvolvimento econômiCo, tendo Bell (1973) como um dos seus precursores, e autores defensores da indústria como propulsora e propagadora do desenvolvimento, como Baumol (1967), Cohen e Zisman (1987), entre outros.
} 
A pluralidade de visões e de interpretações traz à tona uma série de questionamentos quanto à natureza das atividades de serviço. Em primeiro lugar, será serviço uma categoria específica, com características fundamentalmente diferentes de um bem ou produto qualquer? Em segundo, se há características específicas dos serviços, em que fundamentos ou condições econômicas básicas residem? Em terceiro, são essas características aplicáveis a todos os serviços prestados?

É na busca de respostas para estas questões que se define o objetivo deste trabalho, qual seja, estruturar um conjunto de elementos contributivos para uma abordagem conceitual dos serviços na sua acepção ampla e fundamental, capaz de explicá-los nas suas várias particularidades e especificidades.

Como passo analítico inicial, será realizada uma exegese crítica das contribuições teóricas existentes. N este sentido, serão analisados autores clássicos, como Adam Smith (1776), M arx (1867), Say (1803), M ill (1848) e Walras (1874); e autores contemporâneos como G ershuny e M iles (1983), N usbaumer (1984), Walker (1985), M arshall e Wood (1995), e H ill (1976, 1999).. A partir desta releitura apresenta-se então uma proposta de abordagem conceitual.

\section{A VISÃO DOS CLÁSSICOS}

A visão dos clássicos a respeito dos serviços e do seu papel na dinâmica econômica está relacionada fundamentalmente às diferentes concepções a respeito do processo de geração de valor na economia. ${ }^{3}$ Especificamente, é um debate entre, de um Iado, a teoria do valor-trabalho, aqui representada por M arx e Smith, cuja ótica de análise está voltada para os aspectos de oferta, em que a produção industrial é o " hard core" do sistema econômico - , sobrepondo-se a toda e qualquer atividade intangível como é o caso das atividades de serviço - ; e, de outro lado, a teoria do valor-utilidade, aqui representada por Say, M ill e Walras, baseada numa ótica de análise voltada essencialmente para os aspectos de demanda, em que as diferenças técnico-produtivas entre as diversas atividades econômicas - , sejam elas de produção de bens ou de serviços - , não são critérios de definição do caráter produtivo e da relevância econômica das atividades no sistema econômico.

É importante ressaltar que o objetivo aqui é simplesmente estabelecer um diálogo entre visões convencionalmente tidas como antinômicas, sem a preten-

\footnotetext{
${ }^{2}$ Em função da diversidade de interpretações, foram selecionados autores contemporâneos cujos trabalhos problematizam algumas dimensões identificadas como "novas" nas atividades de serviço, questionando as tipologias e classificações que orientam a caracterização e a análise dos serviços. Entretanto, há uma gama de contribuições adicionais, como Ridle (1986), Silvestro et alii (1992), Baily e M aillat (1986), Daniels (1993). Para um levantamento mais amplo e detalhado ver Kon (2004).

${ }^{3}$ Por "clássicos" não se entende aqui uma linha, ou uma escola do pensamento econômico. É um conceito essencialmente "histórico" que se refere aos teóricos situados no período que vai da metade do século XVIII e se estende ao longo do século XIX, cujas obras são fundadoras e balizadoras da metodologia e do objeto da moderna teoria econômica.
} 
são de rever a controvérsia em torno da determinação do valor na economia, mas sim dar conta de um fenômeno moderno: o peso crescente dos serviços na economia.

\section{A Visão de Smith e M arx}

No âmbito da teoria do valor-trabalho, o valor é explicado a partir da quantidade de trabalho incorporada no processo de produção das mercadorias. Entretanto, há diferenças conceituais marcantes entre a visão de Smith (1776) e $M$ arx (1867) a respeito da relação e da função dos elementos constitutivos do processo gerador de valor. Estas diferenças se refletem no conceito de trabal ho produtivo e na interpretação quanto à função econômica e contributiva de valor dos serviços.

A diferença entre trabalho produtivo e improdutivo em Smith está referenciada numa visão material do processo de valorização do capital. Segundo o autor, um bem só tem valor quando é palpável, concreto, visível e estocável, de forma que o trabalho nele aplicado seja reprodutível, capaz de se perpetuar ao longo das transações econômicas, permitindo a aquisição de novos bens e serviços ou seja, a perpetuação do valor pressupõe uma base material de suporte. Portanto trabalho produtivo é todo trabalho reprodutível, que forma uma reserva de valor, concreta e material, de modo a possibilitar a acumulação de riqueza.

Em contrapartida, o trabalho é improdutivo quando não acumula riqueza, não se fixa em nenhum objeto ou bem físico concreto e material, não forma uma reserva de valor que possibilite a aquisição de novos bens e/ou serviços. Este é o caso das atividades de serviço, essencialmente intangíveis. Embora o trabalho realizado nestas atividades seja recompensado da mesma forma que nas demais, através do pagamento de salários, o trabalho realizado não necessariamente assume uma forma material. É um trabalho incapaz de armazenar valor e alavancar novas atividades, não contribuindo direta e ativamente na formação do produto anual de um país, devendo, portanto, ser considerado improdutivo (Smith, 1776, vol II:581-2).

$\mathrm{N}$ a visão de Smith, além de improdutivas, as atividades de serviço são também de baixa rentabilidade. Alijadas do curso da divisão e especialização crescentes do trabalho, são atividades incapazes de gerar lucros suficientes para a sua manutenção e expansão. Por isso mesmo, grande parte destas atividades é realizada pelo governo, financiada a partir de taxas e impostos cobrados pelas autoridades públicas. ${ }^{4}$

De modo contrário a Smith, para M arx não é a materialidade do produto que define se determinada atividade econômica é ou não produtiva, isto é, se ela

\footnotetext{
${ }^{4}$ Incluem-se neste grupo os serviços públicos em geral, onde estão inseridos os serviços de defesa e administração da justiça; os serviços que visam promover a instrução (serviços de educação); e os serviços que visam facilitar o comércio, especificamente os serviços relacionados à infra-estrutura de transporte.
} 
agrega ou não valor, pois a relação de compra e venda não é uma relação entre objetos e coisas, e sim uma relação social. N esta perspectiva, a definição de trabalho produtivo se dá de forma independente do conteúdo material e tangível da mercadoria.

$\mathrm{N}$ a sua formulação, o trabalho é produtivo quando contribui para a formação de um excedente na economia. Para isso, é necessário que a realização do serviço esteja baseada em relações capitalistas de produção, de forma que a subsunção do trabalho ao capital permita a obtenção de mais-valia, isto é, a obtenção de lucros. O u seja, é a capacidade de geração de mais-valia, sob a forma de lucros, que define se uma atividade é ou não produtiva, seja ela uma atividade de produção de bens ou uma atividade de serviço (M arx, 1867, vol II:101-2).

A ausência de uma base material não impede que o serviço tenha valor, principalmente valor de uso. $\mathrm{N}$ a verdade, "um serviço nada mais é que o efeito útil de um valor de uso, seja da mercadoria, seja do trabalho" (M arx, 1867, vol I:159). $\mathrm{N}$ o caso dos serviços de transporte, por exemplo, o valor de uso destes serviços é o "efeito útil" do processo de transporte, que se traduz na existência espacial modificada, pois o que se vende é a locomoção. O u seja, a utilidade do serviço se manifesta no processo de realização de trabalho, sendo impossível a sua circulação e utilização tal como uma mercadoria.

Portanto, na visão de M arx, a tangibilidade da ação da força de trabalho em movimento no circuito produtivo não é prerrogativa para que o trabalho aplicado seja considerado produtivo, ou seja, um trabalho que agrega valor. Do ponto de vista produtivo, o importante é que se estabeleça uma relação capitalista de produção. Esta proposição é válida tanto para a produção de bens quanto a de serviços. N este sentido, M arx avança significativamente em relação a Smith, porque todos os serviços cujo processo produtivo se dê em bases capitalistas de produção são considerados produtivos, independentemente do resultado deste processo ser tangível ou intangível.

Lamentavelmente, porém, mesmo considerando a possibilidade das atividades de serviço serem produtivas, $M$ arx abandona esta perspectiva de análise, dedicando pouca ou quase nenhuma atenção aos serviços. Preocupado em explicar o mundo econômico de sua época, o "mundo das mercadorias", o autor orienta seu esforço teórico à compreensão da lógica de funcionamento da economia capitalista baseada essencialmente na produção industrial. N este contexto, embora as atividades de serviço, desenvolvidas mediante relações capitalistas de produção sejam consideradas produtivas, na visão do autor elas só adquirem importância econômica quando associadas ao processo de valorização do capital industrial - súmula de todos os capitais na economia. Desse modo, os únicos serviços considerados relevantes do ponto de vista econômico são os serviços de comunicação, transporte e armazenamento de mercadorias. A pesar de não contribuírem diretamente na formação do valor, estes serviços evitam a deterioração do valor de uso e tornam o produto acessível para o consumo, proporcionando a realização da mais-valia obtida no processo de produção e, assim, completando o ciclo de valorização do capital. São "um processo de produção dentro do pro- 
cesso de circulação e para o processo de circulação" , ou seja, não constituem custos de circulação isolados, como é o caso dos serviços de comercialização. ${ }^{5}$

\section{A visão dos utilitaristas}

A o conceber o valor do ponto de vista da satisfação das necessidades humanas, ou seja, a partir do valor de uso, os utilitaristas inevitavel mente acabam incluindo os serviços como componentes fundamentais do sistema econômico, pois, assim como os bens materiais, os serviços respondem por uma parte significativa das necessidades humanas. Entretanto, mesmo partindo do princípio da utilidade, verificam-se diferenças entre estes autores, notadamente no que se refere ao conceito de trabalho produtivo.

Centrado no princípio da utilidade, para Say (1803) os processos produtivos não são geradores de objetos, de matéria concreta, mas sim de utilidade. A criação de utilidade é o grande motor da economia, o fato gerador de riqueza. Independentemente das características formais do processo produtivo ou do produto, se mais ou menos tangível, todas as atividades que produzem utilidade são consideradas produtivas. $\mathrm{N}$ esta perspectiva analítica, todos os serviços, de natureza essencialmente intangível, são considerados produtivos, porque são geradores de "utilidade" e, portanto, de riqueza. ${ }^{6}$

A definição de serviço em Say se confunde com trabalho, pois, na sua visão, trabalho nada mais é que a ação da inteligência do homem sobre a natureza e sobre as máquinas e equipamentos para a produção de novos produtos, geradores de utilidade. É o homem colocando a seu serviço as forças da natureza e das máquinas e equipamentos para se satisfazer. Sob esta definição, os serviços são a essência do processo produtivo, pois é através dos serviços prestados pelos vários fatores de produção (terra, trabalho e capital) que se criam novos produtos (Say, 1803:91-2).

Essa definição ampla de serviço proporciona um tratamento particularmente importante na compreensão da dinâmica econômica do setor de serviços, porque estende o conceito de serviço, aplicando-o em toda e qualquer atividade que realize trabalho, ou seja, integrando-os como parte ativa dos processos produtivos. Todavia, esta definição e as suas implicações analíticas para o setor não fo-

\footnotetext{
${ }^{5}$ O s serviços de comercialização, ao invés de contribuírem no processo de agregação de valor, retiram parte da mais-valia agregada durante o processo de produção (M arx, 1867, vol III:102).

"Esse é o caso dos produtos da "indústria humana", denominados por Say de "produtos imateriais", onde se incluem os serviços de lazer, entretenimento, educação e saúde. São produtos intangíveis porque o seu valor (ou utilidade) é consumido no momento de sua produção, mas são produtivos porque têm utilidade, atingem o fim econômico proposto e permitem a aquisição de outros bens através da renda que é gerada (Say, 1803:125). 0 mesmo se aplica aos serviços comerciais. Em contraste à visão de M arx, para Say essas atividades devem ser consideradas produtivas, pois contribuem para 0 equilíbrio do mercado transportando as mercadorias de um "tempo para outro", retirando ou colocando as mercadorias em circulação de acordo com a sua abundância ou escassez no mercado (Say, 1803:129).
} 
ram exploradas em profundidade na obra de Say, sobretudo no que se refere aos atributos e características técnico-econômicas dos serviços, como a intangibilidade e a natureza de fluxo, refletindo a característica única e fundamental destas atividades, que é ser um processo de trabalho?.

A visão de M ill (1848), por sua vez, está baseada numa concepção de trabaIho e numa percepção do papel desempenhado pelo trabal ho humano no processo de agregação de valor fundamentalmente diferente da visão de Say (e de todos os outros autores posteriores de viés utilitarista). $\mathrm{N}$ a sua concepção, é o trabalho humano que proporciona variabilidade e novas combinações de objetos físicos de forma a gerar novos bens e serviços. 0 trabalho é um deslocador de objetos físicos (recursos naturais, máquinas e equipamentos, etc), pois estes objetos em si mesmos não são capazes de se movimentar e gerar valor. A o contrário da definição de Say, não há um "serviço da terra", ou um "serviço do capital", pois os fatores de produção por si só não produzem valor, a agregação de utilidade depende, fundamentalmente, da ação do trabalho humano.

Partindo desta perspectiva da ação transformadora do trabal ho humano, M ill define três tipos de utilidade, classificadas de acordo com a forma em que são incorporadas e fixadas, em objetos ou em seres humanos: i) utilidades fixas e incorporadas em objetos externos; ii) utilidades fixas e incorporadas em seres humanos; iii) utilidades não-fixas, ou não-incorporadas em algum objeto. Destes três tipos de utilidades geradas pela ação do trabalho humano, apenas a primeira, a criação de utilidades permanentes, incorporadas em objetos concretos e estocáveis, caracteriza, segundo M ill, o trabal ho como produtivo, pois permite a acumulação de riqueza.

A concepção de riqueza material subjacente nesta definição de M ill é, em princípio, incompatível com o enfoque utilitarista. Entretanto, o autor adota uma solução conciliadora, propondo que a geração de utilidade permanente pode se dar de forma indireta. N este sentido, para que um serviço seja considerado produtivo o importante é que a utilidade gerada seja incorporada de forma permanente no estoque de riqueza do país. 0 trabalho que cria utilidade incorporada em seres humanos, por exemplo, como é o caso dos serviços de educação, deve ser considerado produtivo na medida em que os homens que se apropriam da utilidade gerada fabricam produtos que, por seu turno, se incorporam no estoque de riqueza do país (M ill, 1848:104).

A mesma solução conciliadora adotada por $\mathrm{M}$ ill entre a intangibilidade inerente ao princípio da utilidade e a concepção de riqueza em bases materiais também se faz presente em Walras (1874). O s serviços são classificados como produtivos e improdutivos de acordo com a durabilidade do produto gerado. Q uando o produto é absorvido diretamente pelo consumo, o serviço é classificado como

\footnotetext{
${ }^{7}$ A natureza de fluxo, embora não fique explícita na sua análise, está presente no destacado papel dos serviços comerciais no deslocamento das mercadorias no tempo e no espaço. Esta característica, conforme apresentado anteriormente, também foi detectada por $M$ arx na sua interpretação a respeito dos serviços de transporte.
} 
consumível. Q uando o serviço é transformado em produtos que podem ser novamente utilizados como capital é considerado produtivo. ${ }^{8}$

Enfim, apesar da defesa de Say quanto ao caráter produtivo dos serviços, verifica-se que os utilitaristas em sua maioria não conseguem fugir internamente de visões predominantemente materiais da economia. N este sentido, acabam relacionando o caráter produtivo dos serviços ao grau de durabilidade dos produtos gerados, ou seja, a uma propriedade física e material. ${ }^{9}$

A discriminação dos clássicos em relação ao conteúdo produtivo dos serviços reproduz, de certa forma, a mesma discriminação feita pelos fisiocratas no início do século XVIII em relação à indústria. A diferença é que para os autores aqui apresentados, a riqueza não se constitui apenas do produto da terra, mas também no produto do trabal ho humano. Conforme será apresentado a seguir, esta concepção material de riqueza se mantém em grande parte dos tratamentos analíticos contemporâneos dados ao setor, sendo transmitida através do próprio padrão de classificação e contabilização das atividades econômicas das estatísticas oficiais.

\section{A VISÃO CONTEM PORÂNEA}

$\mathrm{N} o$ âmbito das abordagens contemporâneas verifica-se um amplo leque de interpretações a respeito das características dos serviços e da forma de classificálos, refletindo focos de análise distintos. De um lado, há autores cuja análise está centrada nas características de oferta, ou seja, nas características do processo de produção e do produto gerado. De outro, há autores mais preocupados com as características de consumo, relacionadas às funções desempenhadas pelos serviços e o público a que se destinam (indústria, famílias e entidades de governo).

Em linhas gerais, a análise focada na oferta define três características que distinguem os serviços das demais atividades econômicas, a saber: fluxo, variedade e uso intensivo de recursos humanos. ${ }^{10} \mathrm{~A}$ característica de fluxo reflete fundamentalmente as propriedades de simultaneidade e de continuidade do proces-

\footnotetext{
${ }^{8} \mathrm{~N}$ a classificação mais geral das atividades de serviço, Walras parte do mesmo pressuposto verificado em Say, em que toda realização de trabalho é traduzida em termos de oferta de serviços prestados pelos vários fatores de produção (trabalho, capital e terra). Ao contrário da visão marxista, o valor é um conceito estritamente técnico e reflete a remuneração dos serviços prestados pelos vários capitais (capital fundiário, máquinas e equipamentos, e capital pessoal).

${ }^{9}$ Parece haver nessa concepção material de riqueza e, assim, na definição de trabalho produtivo, uma preocupação com o senso comum, em que a riqueza está associada à posse de bens materiais, de forma a não levantar polêmica e provocar rejeição às suas idéias ( $M$ ill, 1848:103; M arshall 1890, vol I:75). N a opinião de alguns autores contemporâneos, como N usbaumer (1984), o conceito de utilidade é em sua essência um conceito baseado nas propriedades físicas e materiais dos objetos e, portanto, pouco adequado no tratamento de atividades de natureza essencialmente intangível. Daí a inevitável visão "materialista" do processo de produção e geração de riqueza presente nos autores utilitaristas.
}

${ }^{10}$ Estas características são identificadas especificamente em Thomas (1967). 
so de prestação do serviço. 0 processo só é disparado quando há a solicitação do usuário, de modo que o serviço acontece sob a forma de fluxo, um fluxo de trabalho contínuo no tempo e no espaço. Esta simultaneidade resulta, por seu turno, em duas propriedades, que são a inestocabilidade e a incomensurabilidade. N ão é possível armazenar um serviço, porque ele é consumido tão logo é produzido, daí a sua intangibilidade. ${ }^{11}$ Sendo inestocável e intangível, o seu resultado é de difícil mensuração. $N$ ão se mensura um serviço nos moldes de um bem ou produto qualquer, como dúzias, quilos, metros, etc.

A segunda característica dos serviços, a variedade, se refere à diversidade de técnicas produtivas e às diferenças no tamanho e na margem de lucro das empresas prestadoras de serviço. Por último, a terceira característica, o uso intensivo de recursos humanos, reflete o fato de que, apesar da crescente incorporação do progresso técnico, através de máquinas e equipamentos, os recursos humanos representam o fator produtivo predominante no processo de prestação de serviço, principalmente porque serviço é uma atividade profundamente interativa e, portanto, a natureza relacional da atividade depende essencialmente de recursos humanos para realizar a interface com os consumidores/usuários. Por conta desta característica é atribuído aos serviços o caráter de intensivo em informação.

As abordagens centradas nas características de demanda buscam, por sua vez, analisar os serviços a partir do seu uso, i.e., a partir da função desempenhada e do tipo de consumidor. A hipótese adotada é a de que a dinâmica do setor varia de acordo com o fim último e com o grupo de consumidores a que se destinam os serviços. $N$ este sentido, a classificação destas atividades se dá em duas categorias básicas: serviços intermediários (também denominados de serviços produtivos) e serviços finais (ou serviços de consumo). O s primeiros estariam orientados para o desenvolvimento das atividades produtivas da indústria e das empresas e os últimos para o uso individual (serviços domésticos, lazer, entretenimento) e coletivo (segurança, saúde, educação). ${ }^{12}$

A ausência de unidade teórica e analítica nas abordagens contemporâneas revela, em última instância, uma fragilidade teórico-metodológica. De certa forma, a dicotomia entre as características de oferta e de demanda dos serviços nas abordagens contemporâneas é uma reprodução do debate clássico entre a visão de $M$ arx e Smith de um lado, centrada nos fatores de oferta, e, de outro, a visão de Say, cujo enfoque utilitarista prioriza os fatores de demanda. Porém, com exceção de alguns autores, não há uma referência teórica explícita aos clássicos,

\footnotetext{
${ }^{11}$ Com base na inestocabilidade atribui-se aos serviços o caráter de non-tradeable, isto é, não passível de comercialização, porque não é capaz de ser armazenado e transportado entre localidades distintas.

${ }^{12}$ Seguindo uma linha de análise apoiada nas características de consumo, Browning e Singelman (1978) propõem uma classificação um pouco mais ampla do que a caracterizada pelo convencional binômio entre serviços intermediários e serviços finais. $\mathrm{N}$ a interpretação destes autores, os serviços devem ser classificados de acordo não só com a função econômica, mas também com o tipo de usuário e com a orientação de mercado (market oriented ou non-market oriented). N esta perspectiva, os serviços são agrupados em quatro categorias: serviços produtivos, serviços distributivos, serviços sociais, e serviços pessoais.
} 
principalmente no que se refere às premissas do processo de geração de valor e às implicações teóricas e analíticas sobre o setor de serviços.

Conforme colocado por M arshall e Wood (1995), a fragilidade das abordagens contemporâneas tem suas raízes na própria metodologia de classificação do padrão ISIC - International Standard Industrial Classification - adotada por organismos multilaterais, como O NU, Banco M undial e FM I. Por ser uma metodologia de cunho eminentemente industrial e derivada de uma visão essencialmente material (tangível) da economia, acaba-se tratando as atividades de serviço como uma categoria residual - um saldo decorrente da diferença entre o montante do valor total agregado na economia e o montante agregado nas atividades de indústria e agricultura - , abarcando uma variada gama de atividades sem nenhum nexo conceitual ou analítico. $N$ este sentido, este padrão conduz a uma série de equívocos quanto às características essenciais dos serviços e o seu papel na dinâmica econômica, dificultando a classificação destas atividades na sua crescente diversificação e abrangência, de modo a incorporar as mudanças no processo de produção e as mais modernas funções dos serviços no âmbito da dinâmica econômica contemporânea ${ }^{13}$.

$\mathrm{N}$ a medida em que a economia avança ao longo do século $X X$, tornou-se crescente a percepção de que as inovações tecnológicas no âmbito da informática e das telecomunicações, bem como as inovações organizacionais e as novas formas de comercialização, no que se refere à relação entre produtor e consumidor, conduzem a profundas transformações nos aspectos de produção e consumo dos serviços que se tornam incompreensíveis a partir das características apresentadas como de serviço. Entre as implicações que estas transformações provocam sobre a natureza dos serviços se destaca a redução tendencial da intangibilidade, da simultaneidade, da inestocabilidade e da interatividade pessoal entre prestadores e usuários dos serviços. A combinação destas mudanças resulta, por seu turno, em mudanças nas estruturas e na organização dos mercados. A produção, anteriormente não-contínua, com limitadas economias de escala, passou a ser padronizada (como, por exemplo, as cadeias de fast-food) e reorganizada de maneira mais integrada entre suas unidades, com componentes padronizados e alta divisão do trabalho. 0 utros serviços, freqüentemente operando em pequena escala, com elevada preponderância de firmas familiares e autônomos, passaram a adotar técnicas gerenciais e de controle mais profissionais e eficientes, através da informática e das tecnologias de rede (Kon, 1999).

Em função dessas mudanças nas características técnicas e econômicas dos serviços, verifica-se o surgimento de trabalhos que propõem tipologias e classificações alternativas às visões dicotômicas centradas nos fatores de oferta ou de

\footnotetext{
${ }^{13}$ Serviços que apresentam características fundamentalmente distintas das usualmente atribuídas a este grupo de atividades, como, por exemplo, a natureza capital-intensiva, não são contemplados nestas classificações. N este caso em particular destacam-se os serviços de infra-estrutura econômica, como a distribuição de energia elétrica, água e saneamento básico - contabilizados nas estatísticas oficiais no setor secundário. Ver Silva e M eirelles (2003).
} 
demanda. Dentre estes autores destacam-se Gershuny e M iles (1983), N usbaumer (1984), Walker (1985), M arshall (1988) e H ill (1976, 1999).

$\mathrm{N}$ a visão de $\mathrm{G}$ ershuny e M iles (1983), para compreender as bases históricas e futuras de desenvolvimento do setor serviços é necessária uma perspectiva mais ampla de análise, incluindo não apenas as características de produção e consumo, mas também a organização e a estrutura de produção dos serviços (quadro 1).

Quadro 1

Características e atributos específicos dos serviços (Miles, 1993)

\begin{tabular}{|c|c|}
\hline Processo de Produção & $\begin{array}{l}\text {-Pesados investimentos em prédios e construções: necessidade de } \\
\text { espaço físico para a integração produtor-usuário. } \\
\text {-Alguns são intensivos em mão-de-obra especializada e altamente } \\
\text { qualificada, outros não. } \\
\text {-A organização do processo de trabalho é sempre problemática porque } \\
\text { é difícil controlar e administrar o processo nos mínimos detalhes. }\end{array}$ \\
\hline Produto & $\begin{array}{l}\text { - Intangível e intensivo em informação. } \\
\text { - Inestocável e de difícil transporte. Processo e produto são } \\
\text { praticamente indistinguíveis. } \\
\text {-Quase sempre customizado, atendendo especificidades do mercado } \\
\text { consumidor. }\end{array}$ \\
\hline Consumo & $\begin{array}{l}\text {-A produção e o consumo são instantâneos no tempo e no espaço. } \\
\text {-A produção depende de especificações do consumidor quanto a } \\
\text { design e ao próprio processo de produção. }\end{array}$ \\
\hline Mercado & $\begin{array}{l}\text {-A organização do mercado varia, desde senviços públicos administrados } \\
\text { pelo governo até senviços privados operados em pequena escala por } \\
\text { empresas familiares. } \\
\text {-Via de regra há dispositivos e mecanismos institucionais de regulação } \\
\text { do mercado, com o objetivo de proteger o consumidor e orientá-lo nas } \\
\text { suas decisões de consumo, tendo em vista a dificuldade de } \\
\text { demonstração dos produtos antecipadamente. }\end{array}$ \\
\hline
\end{tabular}

Fonte: Miles (1993)

A singularidade da proposta de N usbaumer (1984) é a ênfase no caráter produtivo das atividades de serviço mesmo quando se trata de serviços fornecidos gratuitamente pela natureza, como a água e 0 ar. ${ }^{14}$ Sua proposta de classificação dos serviços se baseia na posição que estes ocupam no circuito de produção e troca. A nomenclatura utilizada é a das grandes categorias econômicas correntemente utilizadas na classificação dos bens: serviços primários, serviços intermediários e serviços finais.

Partindo de uma perspectiva marxista do processo de valorização do capital, na interpretação de Walker (1985) a diferença básica entre as atividades de produção de bens e as atividades de serviço reside no vínculo que o trabalho aplicado tem com o processo de produção e no resultado deste trabalho, se tangível

${ }^{14} \mathrm{O}$ autor propõe inclusive um conceito amplo de trabalho, i.e., trabalho como "atividade cultural", baseado num conhecimento acumulado, independente de quem o fornece (se trabalhadores ativos ou inativos) e da forma como é pago, se monetária ou não monetária. 
ou intangível. $\mathrm{N}$ a produção de bens o trabalho é direto, aplicado diretamente no processo de produção, com um resultado concreto, expresso no produto físico final. $\mathrm{N}$ a atividade de serviço o trabalho é indireto, ou seja, não está diretamente vinculado ao processo de produção. É uma atividade essencialmente intangível, 0 trabalho realizado não assume uma forma material e reprodutível.

N uma perspectiva oposta, M arshall \& Wood (1995) enfatizam o uso intensivo da informação como fator característico das atividades de serviço, sendo, portanto, atividades fundamentais no processo de valorização do capital, de modo que a produção de bens e a de serviços encontram-se interligadas. D e um lado, serviço é essencialmente intangível, podendo ser avaliado somente quando combinado a outras funções, ou seja, com outros produtos e processos produtivos tangíveis. De outro, o trabalho realizado nas atividades de serviço depende de habilidades de interpretação e processamento de informações; portanto, são atividades de alto conteúdo informacional. É a habilidade de interpretar as informações, atendendo às especificações dos clientes, que faz dos serviços uma atividade especial e de peso cada vez mais crescente na economia, principalmente num contexto onde o conteúdo informacional presente nos processos produtivos e nos produtos é cada vez maior. Q uanto mais complexo o processo produtivo e mais apoiado em habilidades e expertises humanos, e quanto mais orientado para o mercado, mais intenso em serviço.

$\mathrm{N}$ o Q uadro 2 a seguir, encontram-se sistematizadas as propostas al ternativas de classificação das atividades de serviço apresentadas por estes autores.

Quadro 2

Propostas de Classificação das Atividades de Senviço

\begin{tabular}{|c|c|c|}
\hline Autor (es) & Classificação & $\begin{array}{c}\text { Critério de } \\
\text { Classificação }\end{array}$ \\
\hline $\begin{array}{l}\text { Nusbaumer } \\
\text { (1984) }\end{array}$ & $\begin{array}{l}\text {-Serviços Primários: fornecidos pelos fatores de } \\
\text { produção em todas as atividades econômicas. } \\
\text {-Serviços Intermediários: relacionados à comercialização } \\
\text { e distribuição de bens e outros serviços. } \\
\text { - Serviços Finais: relacionados ao bem-estar e à qualidade } \\
\text { de vida dos consumidores finais, englobando inclusive os } \\
\text { serviços públicos de segurança, saúde e educação. }\end{array}$ & $\begin{array}{l}\text { Funções } \\
\text { desempenhadas } \\
\text { e posição } \\
\text { ocupada no } \\
\text { circuito de } \\
\text { produção e } \\
\text { troca. }\end{array}$ \\
\hline $\begin{array}{l}\text { Marshall } \\
\text { (1988) }\end{array}$ & $\begin{array}{l}\text { - Serviços de Processamento de Informações. } \\
\text { - Serviços relacionados à produção de bens e mercadorias. } \\
\text { - Serviços de suporte às necessidades pessoais. }\end{array}$ & $\begin{array}{l}\text { Conteúdo de } \\
\text { expertise e funçao } \\
\text { desempenhada }\end{array}$ \\
\hline $\begin{array}{l}\text { Walker } \\
\text { (1985) }\end{array}$ & $\begin{array}{l}\text { - Serviços de suporte à produção de mercadorias cujo } \\
\text { resultado é um produto concreto e palpável. } \\
\text { - Serviços de circulação de mercadorias, trabalho, dinheiro } \\
\text { e informação e serviços relacionados à aluguel e transferência } \\
\text { de propriedade de ativos. } \\
\text { - Serviços baseados essencialmente em trabalho } \\
\text { (labour services). } \\
\text { - Serviços Governamentais. }\end{array}$ & $\begin{array}{l}\text { Vínculo } \\
\text { estabelecido } \\
\text { no processo } \\
\text { produtivo e } \\
\text { resultado fina } \\
\text { (tangível ou } \\
\text { intangível. }\end{array}$ \\
\hline
\end{tabular}

Fonte: Elaboração própria 
Por fim, ainda no âmbito das abordagens contemporâneas, vale destacar a visão de Hill (1976, 1999), que define serviço como uma mudança nas condições de uma unidade econômica produzida pela atividade de outra unidade. Inspirado na perspectiva marshalliana de que a diferença entre bens e serviços reside na possibilidade do estabel ecimento de direitos de propriedade e, por conseguinte, de comercialização, o autor propõe uma ruptura com a visão convencional de que serviço é um produto intangível, i.e., um bem imaterial. Enfatizando a simultaneidade e a natureza interativa dos serviços, na sua opinião os bens intangíveis, como softwares e filmes, não são serviços porque, mesmo baseados essencialmente em informação, é possível armazenar o conteúdo gerado e comercializá-lo, ou seja, a produção está separada do consumo.

\section{UMA PROPOSTA DE ABORDAGEM}

A hipótese que norteia a proposta de abordagem teórica aqui apresentada é que a natureza específica das atividades de serviço reside no fato de serem essencialmente realização de trabalho - independentemente das características formais do processo produtivo ou do produto resultante deste processo.

A definição de serviço como realização de trabalho não é genuinamente nova. Explícita ou implicitamente os clássicos e os autores contemporâneos sempre trataram os serviços como realização de trabalho. Entretanto, há diferenças básicas, de ordem conceitual e metodológica, em relação à visão destes autores e a abordagem aqui proposta que permitem desmistificar e simplificar um conjunto de características formais e nexos específicos imputados aos serviços, sobretudo no que se refere à natureza dos recursos produtivos utilizados na prestação dos serviços e no resultado do trabal ho realizado - o que resulta também numa concepção diferente a respeito do papel desempenhado na dinâmica econômica.

Da hipótese de que serviço é realização de trabalho, derivam-se três postulados:

1) Serviço é trabalho na sua acepção ampla e fundamental, podendo ser realizado não só através dos recursos humanos (trabalho humano) como também através das máquinas e equipamentos (trabalho mecânico). ${ }^{15}$

2) Serviço é trabalho em processo, ou seja, serviço é trabalho na concepção dinâmica do termo, trabalho em ação.

3) Todo serviço é realização de trabalho, mas nem toda realização de trabaIho é serviço, ou seja, não existe uma relação biunívoca entre serviço e trabalho.

De acordo com o primeiro postulado é possível classificar como atividades de serviço não só aquelas intensivas em recursos humanos como também as capital-intensivas, como é o caso de algumas atividades de infra-estrutura econô-

\footnotetext{
${ }^{15}$ Por trabalho mecânico entende-se aqui todo trabalho que não seja realizado por recursos humanos independente do dispositivo utilizado, se eletro-eletrônico ou mecânico, dentre outros dispositivos. O u seja, inclui qualquer forma de trabalho que não usa a energia do homem como fonte primária.
} 
mica. A demais, é fundamental para a compreensão da configuração dos serviços na economia moderna, tendo em vista que o conteúdo de trabal ho mecânico presente nos processos econômicos tende a se acentuar cada vez mais na medida em que o avanço tecnológico proporciona o surgimento de novos "meios" ou novos ativos físicos (mecânicos) de suporte à realização de trabalho. $\mathrm{O}$ u seja, novos dispositivos de realização de trabalho que se combinam ao trabalho humano ou 0 substituem.

O segundo postulado estabelece uma distinção fundamental entre serviço e produto. Enquanto serviço é trabalho em processo, produto, por outro lado, é o resultado deste processo, ou seja, é um trabalho acumulado, um trabalho objetivado $^{16}$. N este sentido, o produto ao qual os serviços estão relacionados pode ser tangível ou intangível, ou seja, tanto pode ser um bem físico ou uma informação, pois o que caracteriza efetivamente uma atividade como de serviço é, única e exclusivamente, a realização de trabalho.

É possível distinguir serviço não só do produto ao qual está associado como também dos ativos e dos insumos utilizados no processo produtivo, dado que em última instância todos estes são trabalhos acumulados, i.e., são produtos de trabalhos realizados em outros processos produtivos. O u seja, o serviço só se caracteriza enquanto tal na medida em que há realização de trabalho, independente dos insumos utilizados, se tangíveis ou intangíveis, e dos meios de trabalho utilizados, se humanos ou mecânicos.

0 terceiro postulado, por seu turno, permite afirmar que em todas as etapas dos processos econômicos onde se realiza trabalho há um serviço em potencial, mas para que este potencial se realize é necessário que o processo de trabalho em questão seja uma atividade econômica autônoma, estruturada a partir de um arranjo contratual (formal ou informal), onde o propósito de sua constituição é a prestação de trabalho ${ }^{17}$.

o trabalho realizado nas atividades de serviço não é diferente do trabalho realizado nas demais atividades produtivas, pois serviço é apenas trabalho "autonomizado" . O trabal ho tanto pode estar baseado em recursos humanos (mais ou menos qualificados) como em máquinas e equipamentos, porque a forma de trabalho não é o que caracteriza uma atividade de serviço e sim o próprio processo de realização de trabalho.

Sob esta perspectiva, a classificação dos serviços torna-se bastante ampla, sendo possível identificá-los ao longo das etapas de realização de trabalho nos processos econômicos em geral. A naliticamente, conforme se observa no quadro a seguir, a prestação de serviço pode se dar em três níveis, distinguíveis de acor-

\footnotetext{
${ }^{16}$ Produto é "trabalho objetivado" , transformado em valor de uso através da ação do trabalho humano mediante os meios de trabalho ( $M$ arx, 1867, vol I:151).

${ }^{17} \mathrm{As}$ atividades de serviço apresentam em sua origem e constituição uma natureza essencialmente contratual. Etimologicamente, prestação corresponde à ação de satisfazer, do latim prestatione. Do ponto de vista jurídico, prestação é o ato pelo qual alguém cumpre a obrigação que lhe cabe, na forma estipulada no contrato.
} 
do com o processo econômico no qual o serviço se insere: nos processos de trabalho puro, nos processos de transformação e produção ou nos processos de troca e circulação.

\section{Quadro 3}

Classificação dos senviços nos processos econômicos

\begin{tabular}{|c|c|c|}
\hline $\begin{array}{l}\text { Processo } \\
\text { Econômico }\end{array}$ & Tipo de serviço & Exemplos \\
\hline $\begin{array}{l}\text { Processo de } \\
\text { trabalho puro }\end{array}$ & $\begin{array}{l}\text { Serviço puro } \\
\text { Consiste em realizar um trabalho único } \\
\text { e exclusivo. O resultado do processo de } \\
\text { trabalho é o próprio trabalho, não há } \\
\text { necessariamente um produto resultante. }\end{array}$ & $\begin{array}{l}\text { Serviços domésticos; Serviços } \\
\text { de entretenimento e lazer; } \\
\text { Serviços de consultoria; } \\
\text { Serviços de assistência técnica; } \\
\text { Serviços de pesquisa e } \\
\text { desenvolvimento de produtos; } \\
\text { Serviços de saúde e educação; } \\
\text { Serviços governamentais de } \\
\text { defesa e segurança, etc. }\end{array}$ \\
\hline $\begin{array}{l}\text { Processo de } \\
\text { transformação }\end{array}$ & $\begin{array}{l}\text { Serviço de transformação } \\
\text { Consiste em realizar o trabalho necessário } \\
\text { à transformação de insumos e } \\
\text { matérias-primas em novos produtos. }\end{array}$ & $\begin{array}{l}\text { Serviços de alimentação; } \\
\text { Serviços decorrentes da } \\
\text { terceirização de etapas do } \\
\text { processo de transformação. }\end{array}$ \\
\hline $\begin{array}{l}\text { Processo de troca } \\
\text { e circulação }\end{array}$ & $\begin{array}{l}\text { Serviço de troca e circulação } \\
\text { Consiste em realizar o trabalho de troca } \\
\text { e circulação, seja de pessoas, bens } \\
\text { (tangíveis ou intangíveis), moeda, etc. }\end{array}$ & $\begin{array}{l}\text { Serviços Bancários; } \\
\text { Serviços Comerciais; } \\
\text { Serviços de armazenamento } \\
\text { e transporte; Serviços de } \\
\text { comunicação; Serviços } \\
\text { de distribuição de energia } \\
\text { elétrica, água, etc. }\end{array}$ \\
\hline
\end{tabular}

Fonte: Elaboração própria

É importante notar que essa classificação dos serviços é apenas um recurso analítico para a compreensão das várias formas possíveis de ocorrência de tais atividades no sistema econômico, pois todo e qualquer serviço é única e exclusivamente realização de trabalho em processo. Ao adotar essa definição estabelece-se aqui uma visão ampla e geral da natureza e função econômica dos serviços no contexto econômico e social, independentemente de suas manifestações morfológicas ou tópicas. $\mathrm{N}$ a prática, é possível separar contratualmente as várias etapas de realização de trabalho, haja visto o movimento de terceirização ocorrido maciçamente nas indústrias nos últimos tempos. Entretanto, não se supõe nessa classificação a formação de arranjos contratuais definidos por movimentos estratégicos das empresas ou moldados por um arcabouço institucional e regulatório público.

Vale dizer, as condições de realização de trabalho podem mudar (e sempre mudam); os arranjos contratuais sobre os quais os serviços se estruturam podem 
mudar; mas a essência dos serviços continuará a ser realização de trabalho em processo.

É o entendimento de ser trabalho em processo, ou fluxo de trabalho, que permite tornar inteligíveis os atributos comumente reconhecidos pelos autores clássicos e contemporâneos nas atividades de serviço, como a intangibilidade, a simultaneidade e a inestocabilidade.

Em primeiro lugar, a natureza intangível dos serviços está associada à sua natureza de processo e não ao produto resultante, sendo processo é a priori intangível. Por ser um processo de trabalho, a prestação de serviço tende a acontecer pari passu ao consumo, ou seja, a produção é simultânea ao consumo. A produção só acontece a partir do momento em que o serviço é demandado e se encerra assim que a demanda é atendida. Esta simultaneidade entre 0 ato de produzir e consumir torna, por sua vez, o serviço inestocável, pois o seu fornecimento se dá de forma contínua no tempo e no espaço e ele se extingue tão logo se encerra o processo de trabalho.

Sendo fluxo de trabalho os serviços apresentam também como atributo característico a interatividade. É condição sine qua non para a prestação de qualquer serviço a interação entre prestadores e usuários de serviço, pois é impossível a existência de um fluxo contínuo de trabalho sem um canal interativo que lhe dê suporte. Esta interação tanto pode ser pessoal e direta, através da presença física de prestadores e usuários, como essencialmente técnica, definida a partir de meios físicos de conexão, como as redes físicas de fios, cabos e dutos utilizadas para a prestação de serviços de infra-estrutura econômica. ${ }^{18}$

A natureza de fluxo revela ainda outro atributo dos serviços, que é a irreversibilidade. Ao disparar o processo de realização de trabalho não é possível revertê-lo. É possível interrompê-lo, mas não revertê-lo, porque parte de sua ação e de seu efeito já se deu ao longo do processo de trabalho. ${ }^{19}$

Confundir serviço com os atributos do produto final, bem como com os ativos ou insumos utilizados no processo produtivo, é um equívoco crucial na compreensão da sua dinâmica econômica, pois impede a identificação do determinante fundamental do valor gerado pelo serviço, que é a realização de trabalho.

A o contrário das hipóteses adotadas por vários autores contemporâneos, a caracterização de uma atividade de serviço e o seu conteúdo produtivo independe da forma como esse trabalho é consumido ou incorporado no processo produti-

\footnotetext{
${ }^{18} \mathrm{~A}$ inestocabilidade configura, em princípio, o serviço como non tradeable, isto é, não passível de comercialização. Entretanto o estabelecimento de redes físicas de interconexão, ou redes comerciais e pontos de representação, como as franquias, por exemplo, torna os serviços comercializáveis.

${ }^{19}$ Em última instância, prestar um serviço, seja ele qual for, consiste em cumprir uma promessa de atendimento de especificações de demanda, firmadas ex-ante em contratos (formais ou informais) que se realizarão ex-post, pois sendo trabalho em processo, não se conhece a priori o resultado final do serviço. Esta incerteza quanto ao resultado final e a irreversibilidade criam fortes laços entre prestadores e usuários que se configuram em significativas barreiras de mercado - daí a coexistência de empresas variadas, tanto em termos de estrutura quanto de desempenho, no setor. Ver Silva e M eirelles (2003).
} 
vo, se direta ou indiretamente. 0 grau de intangibilidade do resultado do processo de trabalho ou o uso a que se destina não interfere na geração de valor. Sendo trabalho em processo, os serviços são em essência geradores de valor. Se não há realização de trabalho, não há serviço e, portanto, não há geração de valor.

Q uando não há realização de trabalho tem-se, na verdade, a exploração de um trabalho já realizado em processos produtivos anteriores, que foi acumulado e consubstanciado nesses ativos. $\mathrm{O}$ u seja, não há geração de valor, e sim exploração de renda. Este é o caso, por exemplo, do aluguel de imóveis, que consiste essencialmente na exploração do trabalho de construção civil realizado anteriormente, que se consubstanciou no imóvel. Da mesma forma, a venda de licenças para o uso de softwares também consiste na exploração de um trabalho gerado anteriormente, que foi a concepção do software..$^{20}$

Enfim, a tese aqui defendida é que serviço não é improdutivo, ou seja, não está isolado do processo de geração de riqueza porque é intangível, como defendia Smith, ou porque não está submetido à lógica de valorização do capital industrial, conforme interpretado por $\mathrm{M}$ arx. Da mesma forma, serviço não pode ser produtivo somente quando gera uma utilidade permanente ou durável, conforme definido por $\mathrm{M}$ ill e Walras. $\mathrm{N}$ a verdade, serviço é simplesmente realização de trabalho em processo e é a sua existência que garante a incessante reprodução do capital aplicado no setor ao qual está vinculado, o que permite tratá-los de forma endógena e integrada no sistema econômico.

\section{CONSIDERAÇÕES FINAIS}

A questão fundamental na análise conceitual dos serviços consiste em compreender que serviço é fundamentalmente diferente de um bem ou de um produto. Serviço é trabalho em processo, e não o resultado da ação do trabalho; por esta razão elementar, não se produz um serviço, e sim se presta um serviço. Esta perspectiva de abordagem conceitual incita mudanças significativas no tratamento até agora dado a estas atividades, tanto em termos de classificação e quantificação nas contas nacionais, quanto do ponto de vista do seu papel na dinâmica econômica.

Por um lado, a visão essencialmente material e tangível da economia implicitamente presente nos padrões de contabilidade nacional e internacional conduz a um tratamento, classificação e mensuração dos serviços como um produto (um produto intangível) e não como processo. N este sentido, estes padrões podem ser fonte de questionamentos e até equívocos não desprezíveis de mensuração do valor agregado pelos serviços. Grande parte das atividades usualmente consideradas como serviço podem ser apenas atividades baseadas na exploração de renda

\footnotetext{
${ }^{20}$ Somente quando se tem manutenção e atualização do software vendido é que se pode considerar a atividade como um serviço, pois há um trabalho sendo realizado.s
} 
de um trabalho já realizado anteriormente, como é o caso de patentes, licenças para uso de softwares, aluguel de imóveis, entre outros. Enquanto que atividades essencialmente de serviço, como as de infra-estrutura econômica, não são tratadas como tal.

Por outro lado, há um paradoxo saliente nessas classificações que é o tratamento dos serviços como uma categoria residual, decorrente da diferença entre 0 montante de valor total agregado na economia e o montante agregado nas atividades de indústria e agricultura. Como conciliar esta visão residual com a importância dominante dos serviços, hoje registrada nas estruturas produtivas de valor em economias desenvolvidas e em desenvolvimento; aliás, medida de valor informada por essa mesma visão residual?

\section{REFERÊN CIAS BIBLIOGRÁFICAS}

BAILY, A.S. e M AILLAT, D. (1986) Le secteur Tertiare en question: Activites de service, development economique et spatial. Genebra: Editions R egionales Europeenes.

BAUM O L, W.J . (1985) "Productivity policy and the service sector". In: Inman R. P. (ed) M anaging the service economy. Cambridge University Press: Cambridge, 301-17.

BELL, D. (1973) The Coming of Post-Industrial Society: A Venture in Social Forecasting. N ew York: Basic Books.

BRO W N IN G , H.C., SIN GELM AN N (1978) "The transformation of the US Labour Force: the interaction of industry and occupation". Politics and Society, 8 (7-4), 481-509.

COHEN , S. \& ZYSM AN , J. (1987) M anufacturing matters: the myth of the post-industrial economy. $\mathrm{N}$ ew York: Basic Books.

DAN IELS, P.W. (1993) Service Industries in the World Economy. Oxford: Backwell Pub.

FISCHER, A. G. (1939) "Production, primary, secondary and tertiary". E conomic Record, June.

GERSH UN Y, J.I, M ILES, I.D. (1983) The N ew Service Economy - The Transformation of Employment in Industrial Societies. London: Frances Pinter.

HILL, T.P. (1976) "O n goods and services". Review of I ncome and Wealth, 315-38.

HILL, T.P. (1999) "Tangibles, intangibles and services: a new taxonomy for the classification of output". Revue Canadienne d'E conomique, Canada: vol. 32, № 2 , april 1999, 426-46.

KO N , A nita. (2004) E conomia de Serviço - Teoria e Evolução no Brasil. Rio de Janeiro: Elsevier, 2004.

KON, A nita. (1999) "Sobre as atividades de serviço: revendo conceitos e tipologias". R evista de E conomia Política, São Paulo: vol. 19, № 2 (74), abril-junho/1999, 64-83.

KON , A nita. (2001) "A tividades Terciárias: Induzidas ou Indutoras do Desenvolvimento EconômiCo". M imeo. Paper apresentado no Seminário Raul Prebisch, IE-UFRJ.

M ARSH ALL, Alfred (1890) The principles of Economics. São Paulo: Ed. N ova Cultural, 1982.

M ARSH ALL, J. N . (1988) Services and uneven development. Oxford: O xford University Press.

M ARSH ALL, J. N . e Wood, P.A (1995) Services \& Space: Key Aspects of U rban and R egional D evelopment. Longman Scientific \& Technical Publishers.

M ARX, Karl (1867) O Capital. São Paulo: Ed. N ova Cultural, 1985.

M ILL, J ohn Stuart (1848) Princípios de E conomia Política. São Paulo: Ed. N ova Cultural, 1996.

N APO LEO N I, Claudio (1977) O Valor na Ciência E conômica. Lisboa/São Paulo: Ed. Presença/M artins Fontes.

N USBA UM ER, Jacques (1984) L es services: nouvelle donne de l'economie. Paris: Economica.

RIDDLE, D.I. (1986) Service-L ed G rowth. The R ole of the Service Sector in World D evelopment. N ova York: Praeger Publishers.

SAY, J ean-Baptiste (1803) Tratado de E conomia Política. São Paulo: A bril Cultural, 1983. 
SILVA E M EIRELLES, D. (2003) O setor de serviços e os serviços de infra-estrutura econômica. Tese de Doutorado, Universidade Federal do Rio de Janeiro.

SILVESTRO, R.L., FITZGERALD, R., JOH NSTON \& C. VOSS (1992) "Toward a Classification of Service Process" International J ournal of Service Industry M anagement, 3/3, 1992.

SM ITH , Adam (1776) Riqueza das N ações. Lisboa: Edição da Fundação Calouste Gulbenkian, 1999.

TH O M AS, G.B. (1967) "M anpower Problems in the Service Sector". International Seminars Paris: 1966-2, OECD.

WALKER, Richard (1985) "Is there a service economy?" Science and Society, vol. 49, № 1: 42-83.

WALRAS, L. (1874) Elementos de E conomia Política Pura. São Paulo: Ed. N ova Cultural, 1996. 